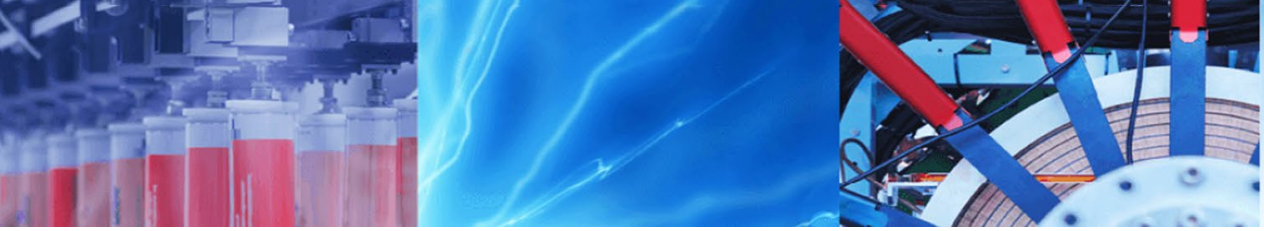

Research Article

\title{
Uncertainty assessment of wellbore stability analysis in horizontal sections
}

\author{
Seyyed Shahab Tabatabaee Moradi ${ }^{1}$. Nikolay Ivanovich Nikolaev ${ }^{2}$
}

Received: 3 August 2019 / Accepted: 12 February 2020 / Published online: 18 February 2020

(c) Springer Nature Switzerland AG 2020

\begin{abstract}
Over the last years, horizontal wells have found applications in many different geological and technical situations to enhance the production rate from the oil and gas reservoirs. However, well instability problems are often reported during construction of these types of wells. To mitigate instability problems, which are usually difficult and costly to solve, well stability analysis are conducted before the construction process begins. Different geomechanical and mathematical models that are used in the well stability studies, do not include the uncertainty assessments of the models. As majority of input parameters into the geomechanical models are subjected to some extent of errors and uncertainties, therefore, it is essential to quantify the uncertainty associated with the output of the geomechanical models. In this work, a Monte Carlo simulation technique is applied to quantify the uncertainty in the output of a poroelastic model to make more reliable decisions in the well construction process.
\end{abstract}

Keywords Well stability · Poroelastic model · Monte Carlo simulation · Uncertainty

\section{Introduction}

Horizontal wells are classified as one type of directional wells with inclination angles larger than 80 degrees. Over the last years, horizontal drilling has been used to enhance hydrocarbon production in thin layers, fractured formations, formations with water and/or gas coning problem and reservoirs with heavy oil. Additionally, horizontal wells have found applications in water, thermal and $\mathrm{CO}_{2}$ flooding [1].

Compared to vertical wells, horizontal wells are more expensive and difficult to drill. However, they are preferred over vertical wells in especial geological and technical conditions, as increased wellbore exposure to the producing formation in horizontal wells leads to higher production rates.

Many serious instability issues are reported in directional and horizontal wells, especially during drilling in highly stressed formations like weak carbonates, shales and loose unconsolidated sandstones. Instability problems are often complicated and expensive to solve and may endanger the whole well drilling and completion process. Therefore, wellbore stability analysis should be conducted before drilling operation to study the possible insatiability issues and mitigate them [2-4].

Understanding the rock behavior around the borehole is the key parameter of wellbore stability analysis. Rock behavior is determined by studying numerous controllable and non-controllable parameters, such as state of in situ stresses in the region, formation pressure, rock strength properties, temperature, pressure, drilling fluid characteristics and well trajectory specifications [5].

Many researchers have developed different geomechanical models, i.e. pure elastic, poroelastic, thermoporoelastic and chemical models to study the rock behavior around the borehole and finally evaluate the stability

Seyyed Shahab Tabatabaee Moradi, s.sh.tabatabaee@gmail.com | ${ }^{1}$ Faculty of Petroleum and Natural Gas Engineering, Sahand University of Technology, Tabriz, Iran. ${ }^{2}$ Well Drilling Department, Saint-Petersburg Mining University, Saint-Petersburg, Russian Federation.

SN Applied Sciences (2020) 2:437 | https://doi.org/10.1007/s42452-020-2237-y 
of the wellbore [6-8]. However, none of the mentioned studies includes the uncertainty assessment related to the model performance.

Generally, vast variety of input parameters are required for each of the mentioned models, the accuracy of which determines the model performance efficiency in wellbore instability prediction. It should be noted that most of the input parameters are subjected to some extent of errors and uncertainties, which leads to the inaccurate model outputs and false estimation of wellbore stability. Errors in the measurement tools, interpretation methods, human mistakes, and simplifying assumptions are considered as the main sources of uncertainty in the input parameters.

Quantitative probabilistic methods can be used to determine the effect of uncertainties in input parameters on the performance of geomechanical models. This procedure leads to more reliable and accurate results during the wellbore stability analysis [9].

In this research, a simple poroelastic model and Mogi-Coulomb failure criterion are used to analyze the stability of a horizontal wellbore. Results of the model are represented as the minimum mud weight, which is essential to maintain the wellbore stability. In addition, Monte Carlo simulation technique is applied to quantify uncertainty associated with the model output.

\section{Theory and methods}

The workflow of this study consists of two main parts (Fig. 1). During part I (a), a poroelastic model is selected to analyze the stress distribution around the wellbore. In part I (b) Mogi-Coulomb failure criterion is selected to compare the altered stresses around the wellbore with the rock strength characteristics and consequently decide on the well stability. In part I (c), errors associated with the model input variables to poroelastic model are quantified. In part II, the Monte
Carlo simulation has been used to quantify the model output uncertainty.

\subsection{Poroelastic model}

Poroelastic models have been developed based on the main assumption that the rock is a porous medium, which is filled by different fluids. These models can predict mechanical responses of fluid saturated porous rocks with good accuracy, especially in wells with normal or moderate temperatures. Mathematical expressions 1-6 represent a poroelastic model, which are used to analyze the state of stresses around the borehole $[10,11]$.

$$
\begin{aligned}
\sigma_{\mathrm{rr}}= & \left(\frac{\sigma_{\mathrm{x}}+\sigma_{\mathrm{y}}}{2}\right)\left(1-\frac{r_{w}^{2}}{r^{2}}\right)+\left(\frac{\sigma_{\mathrm{x}}-\sigma_{\mathrm{y}}}{2}\right)\left(1+3 \frac{r_{w}^{4}}{r^{4}}-4 \frac{r_{w}^{2}}{r^{2}}\right) \cos 2 \theta \\
& +\sigma_{\mathrm{xy}}\left(1+3 \frac{r_{w}^{4}}{r^{4}}-4 \frac{r_{w}^{2}}{r^{2}}\right) \sin 2 \theta+\frac{r_{w}^{2}}{r^{2}} \mathrm{P}_{\mathrm{w}}-\alpha \mathrm{Po}
\end{aligned}
$$

$$
\begin{aligned}
\sigma_{\theta \theta}= & \left(\frac{\sigma_{\mathrm{x}}+\sigma_{\mathrm{y}}}{2}\right)\left(1+\frac{r_{w}^{2}}{r^{2}}\right)-\left(\frac{\sigma_{\mathrm{x}}-\sigma_{\mathrm{y}}}{2}\right)\left(1+3 \frac{r_{w}^{4}}{r^{4}}\right) \cos 2 \theta \\
& -\sigma_{\mathrm{xy}}\left(1+3 \frac{r_{w}^{4}}{r^{4}}\right) \sin 2 \theta-\frac{r_{w}^{2}}{r^{2}} \mathrm{P}_{\mathrm{w}}-\alpha \mathrm{PO}
\end{aligned}
$$

$$
\sigma_{\mathrm{zz}}=\sigma_{\mathrm{z}}-v\left[2\left(\sigma_{\mathrm{x}}-\sigma_{\mathrm{y}}\right) \frac{r_{w}^{2}}{r^{2}} \cos 2 \theta+4 \sigma_{\mathrm{xy}} \frac{r_{w}^{2}}{r^{2}} \sin 2 \theta\right]-\alpha \mathrm{Po}
$$

$$
\begin{aligned}
\sigma_{\mathrm{r} \theta}= & \left(\frac{\sigma_{\mathrm{x}}-\sigma_{\mathrm{y}}}{2}\right)\left(1-3 \frac{r_{w}^{4}}{r^{4}}+2 \frac{r_{w}^{2}}{r^{2}}\right) \sin 2 \theta \\
& +\sigma_{\mathrm{xy}}\left(1-3 \frac{r_{w}^{4}}{r^{4}}+2 \frac{r_{w}^{2}}{r^{2}}\right) \cos 2 \theta
\end{aligned}
$$

Fig. 1 Workflow of the paper

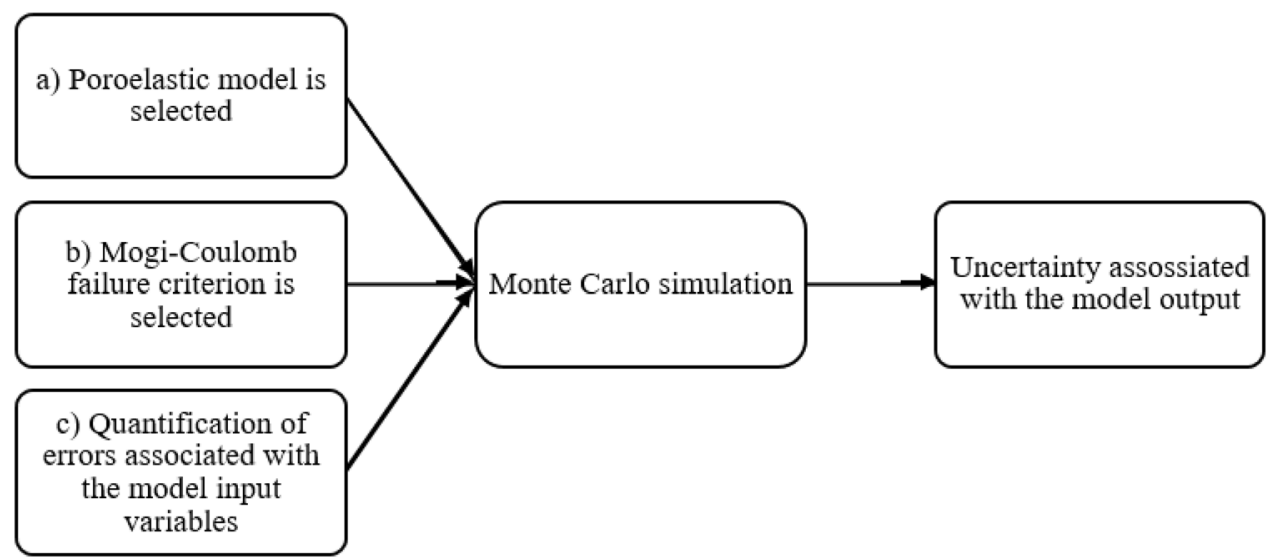


$\sigma_{\theta z}=\left(-\sigma_{x z} \sin \theta+\sigma_{y z} \cos \theta\right)\left(1+\frac{r_{w}^{2}}{r^{2}}\right)$

$\sigma_{\mathrm{rz}}=\left(-\sigma_{\mathrm{xz}} \cos \theta+\sigma_{\mathrm{yz}} \sin \theta\right)\left(1-\frac{r_{w}^{2}}{r^{2}}\right)$

$\sigma_{\mathrm{rr}}, \sigma_{\theta \theta}$ and $\sigma_{\mathrm{zz}}$ are radial, hoop and axial stress respectively, $\sigma_{\mathrm{r} \theta}, \sigma_{\theta z}$ and $\sigma_{\mathrm{rz}}$ are components of shear stress, $P_{w}$ is the hydrostatic wellbore pressure, $\mathrm{rw}$ is the borehole radius, $P_{0}$ is the formation pore pressure, $\theta$ is the point location angle, $v$ is Poisson's ratio and $a$ is the Biot's effective stress coefficient. $\sigma_{x}, \sigma_{y}, \sigma_{z}, \sigma_{x y}, \sigma_{x z}$ and $\sigma_{y z}$ are the local stress distribution around the borehole in Cartesian coordinate. At wellbore wall of a horizontal section $\left(r=r_{w}\right)$, these equations simplify as [12]:

$\sigma_{\mathrm{rr}}=\mathrm{P}_{\mathrm{w}}-\alpha \mathrm{Po}$

$\sigma_{\theta \theta}=\left(\sigma_{x}+\sigma_{y}\right)-2\left(\sigma_{x}-\sigma_{y}\right) \cos 2 \theta-4 \sigma_{x y} \sin 2 \theta-P_{w}-\alpha P o$

$\sigma_{z z}=\sigma_{z}-v\left[2\left(\sigma_{x}-\sigma_{y}\right) \cos 2 \theta+4 \sigma_{x y} \sin 2 \theta\right]-\alpha P o$

$\sigma_{\mathrm{r} \theta}=0$

$\sigma_{\theta z}=2\left(-\sigma_{x z} \sin \theta+\sigma_{y z} \cos \theta\right)$

$\sigma_{\mathrm{rz}}=0$

Local stress distribution around the borehole in Cartesian coordinate are expressed based on the in situ stresses in the virgin formation as follows [13]:

$\sigma_{x}=\left(\sigma_{H} \cos ^{2} \alpha_{a}+\sigma_{h} \sin ^{2} \alpha_{a}\right) \cos ^{2} i+\sigma_{v} \sin ^{2} i$

$\sigma_{y}=\sigma_{H} \sin ^{2} \alpha_{a}+\sigma_{h} \cos ^{2} \alpha_{a}$

$\sigma_{\mathrm{z}}=\left(\sigma_{\mathrm{H}} \cos ^{2} \alpha_{\mathrm{a}}+\sigma_{\mathrm{h}} \sin ^{2} \alpha_{\mathrm{a}}\right) \sin ^{2} \mathrm{i}+\sigma_{\mathrm{v}} \cos ^{2} \mathrm{i}$

$\sigma_{x y}=0.5\left(\sigma_{h}-\sigma_{H}\right) \sin 2 \alpha_{a} \cos i$

$\sigma_{x z}=0.5\left(\sigma_{H} \cos ^{2} \alpha_{a}-\sigma_{h} \sin ^{2} \alpha_{a}-\sigma_{v}\right) \sin 2 i$

$\sigma_{y z}=0.5\left(\sigma_{h}-\sigma_{H}\right) \sin 2 \alpha_{a} \sin \mathrm{i}$

where $\sigma_{v}, \sigma_{H}$ and $\sigma_{h}$ are the vertical, maximum and minimum horizontal in situ stresses respectively. Angles i and aa are the inclination and azimuth angles of the wellbore.

\subsection{Mogi-Coulomb failure criterion}

For geomechanical study of the wellbore stability, a failure criterion should be used to compare the calculated stress distribution around the well with rock mechanical strength. Based on the comparison result, decision will be made about stability or instability of the well.

Mogi-Coulomb failure criterion, which is a shear failure criterion, is selected, as it is simple to use and also considers the effect of intermediate principal stress, influence of which on rock failure mechanisms can not be neglected [14]. Basic concepts of the Mogi-Coulomb failure criterion were firstly presented by Mogi. He indicated that brittle fracture always occurs along a plane, which strikes in the intermediate principal directions. Later Al-Ajmi and Zimmerman developed Mogi-Coulomb model as follows [15, 16]:

$\tau_{\text {oct }}=\mathrm{a}+\mathrm{b} \sigma_{\mathrm{m} 2}$

where $\mathrm{a}$ and $\mathrm{b}$ are constants, defined by rock properties, $\sigma_{\mathrm{m} 2}$ is the mean stress and $\tau_{\text {oct }}$ is the octahedral shear stress:

$\sigma_{\mathrm{m} 2}=\frac{\sigma_{1}+\sigma_{3}}{2}$

$\tau_{\mathrm{oct}}=\frac{1}{3} \sqrt{\left(\sigma_{1}-\sigma_{2}\right)^{2}+\left(\sigma_{2}-\sigma_{3}\right)^{2}+\left(\sigma_{1}-\sigma_{3}\right)^{2}}$

$a=\frac{2 \sqrt{2}}{3} c \cos \emptyset$

$b=\frac{2 \sqrt{2}}{3} \sin \varnothing$

where $C$ is rock cohesion, $\varnothing$ is internal friction angle, $\sigma_{1}, \sigma_{2}$, and $\sigma_{3}$ are maximum, intermediate and minimum principal stresses respectively.

\subsection{Quantification of errors associated with input variables}

Input variables to a poroelastic models can be classified in four groups:

- Well trajectory specifications (azimuth and inclination angles and depth).

- Rock mechanical properties (Poisson ratio, Young modulus, cohesion, Biot's effective stress coefficient and internal friction angle).

- State of in situ stresses.

- Formation pore pressure. 
Among these variables, true values of well trajectory specifications are known exactly and therefore no errors are associated with them.

The last three groups of input variable, i.e. rock mechanical properties, state and direction of in situ stresses and formation pore pressure are usually obtained by interpretation of indirect measurements (such as well log and well test data), which leads to some extent of errors and uncertainties in obtained values of the variables. Range of errors associated with the variables, obtained by indirect methods are usually known (Table 1) [17].

\subsection{Monte Carlo simulation}

Monte Carlo simulation technique is considered as a numerical simulation, which uses random samples from the uncertain space of input variables. Random numbers of input variables are generated based on their cumulative distribution function. For each random number, the system is simulated and output of the system is calculated. Therefore, it will be possible to calculate the occurrence probability of each output using numerical methods [18].

One of the factors that controls the quality of Monte Carlo simulation is trial number, which is the number of samples that are selected randomly from their distribution function. The minimum trial number for a specific coverage probability of simulation is given by following formula [19]:

$N>\frac{10^{4}}{1-p}$

where $\mathrm{N}$ is the minimum trial number in Monte Carlo simulation and $p$ is coverage probability of the simulation. Considering a $90 \%$ of coverage probability, at least 100,000 trials of simulations should be run.

Table 1 Range of errors associated with input variables

\begin{tabular}{lll}
\hline Input variable & Unit & $\begin{array}{l}\text { Error in the indirect } \\
\text { measurement, \% }\end{array}$ \\
\hline Formation pore pressure & $\mathrm{MPa}$ & 30 \\
Rock mechanical properties & - & 10 \\
Poison ratio & $\mathrm{MPa}$ & 50 \\
Cohesion & $\circ$ & 20 \\
Internal friction angle & & \\
State of in situ stresses & $\mathrm{MPa}$ & 5 \\
Minimum horizontal stress & $\mathrm{MPa}$ & 15 \\
Maximum horizontal stress & $\mathrm{MPa}$ & 10 \\
Vertical stress &
\end{tabular}

SN Applied Sciences

\section{Results and discussion}

Using set of data presented in Table 2, value of errors presented in Table 1 and assuming that all input variables are normally distributed, the Monte Carlo simulation technique with a 100,000 sample number is performed to quantify uncertainties associated with the poroelastic model output.

Figure 2 shows the probability of well stability as a function of mud pressure at azimuth angle of 40 degrees.

As it can be seen, at mud pressures larger than $50 \mathrm{MPa}$, the probability of well stability is $100 \%$. 3D Figs. 3 and 4 show probability of well stability for different mud pressures and azimuth angles.

Results show that at azimuth angles of 0 and 180 degrees, the probability of well stability is higher than other azimuth angles at the same mud pressure.

It is also evident that the probability of the well stability does not change significantly at different azimuth angles. However, drilling parallel to the direction of the minimum horizontal stress leads to higher probability of the well stability.

Presented results in figures can be used to quantify the certainty level during determination of mud pressure,

Table 2 Input variables to the poroelastic model

\begin{tabular}{ll}
\hline Input parameter & Value \\
\hline Vertical stress, MPa & 60 \\
Maximum horizontal stress, MPa & 70 \\
Minimum horizontal stress, MPa & 65 \\
Internal friction angle, degree & 31 \\
Cohesion, MPa & 22 \\
Poison ratio & 0.3 \\
Pore pressure, MPa & 35 \\
\hline
\end{tabular}

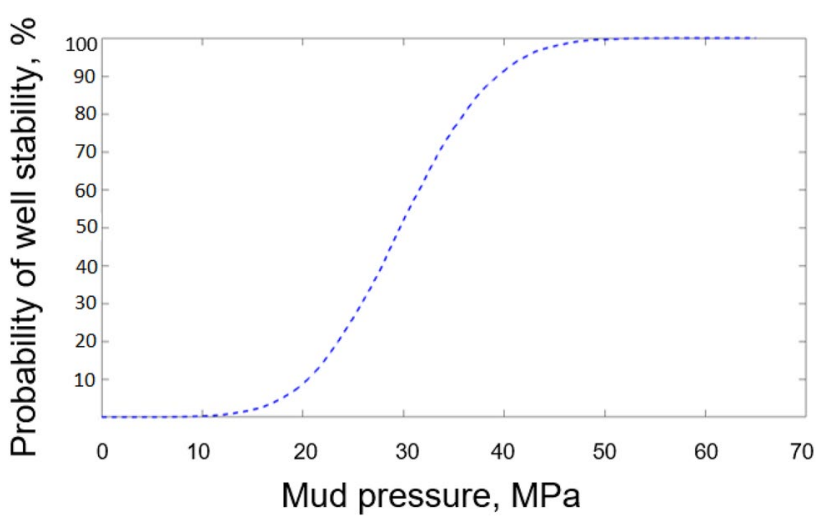

Fig. 2 Probability of well stability as a function of mud pressure 


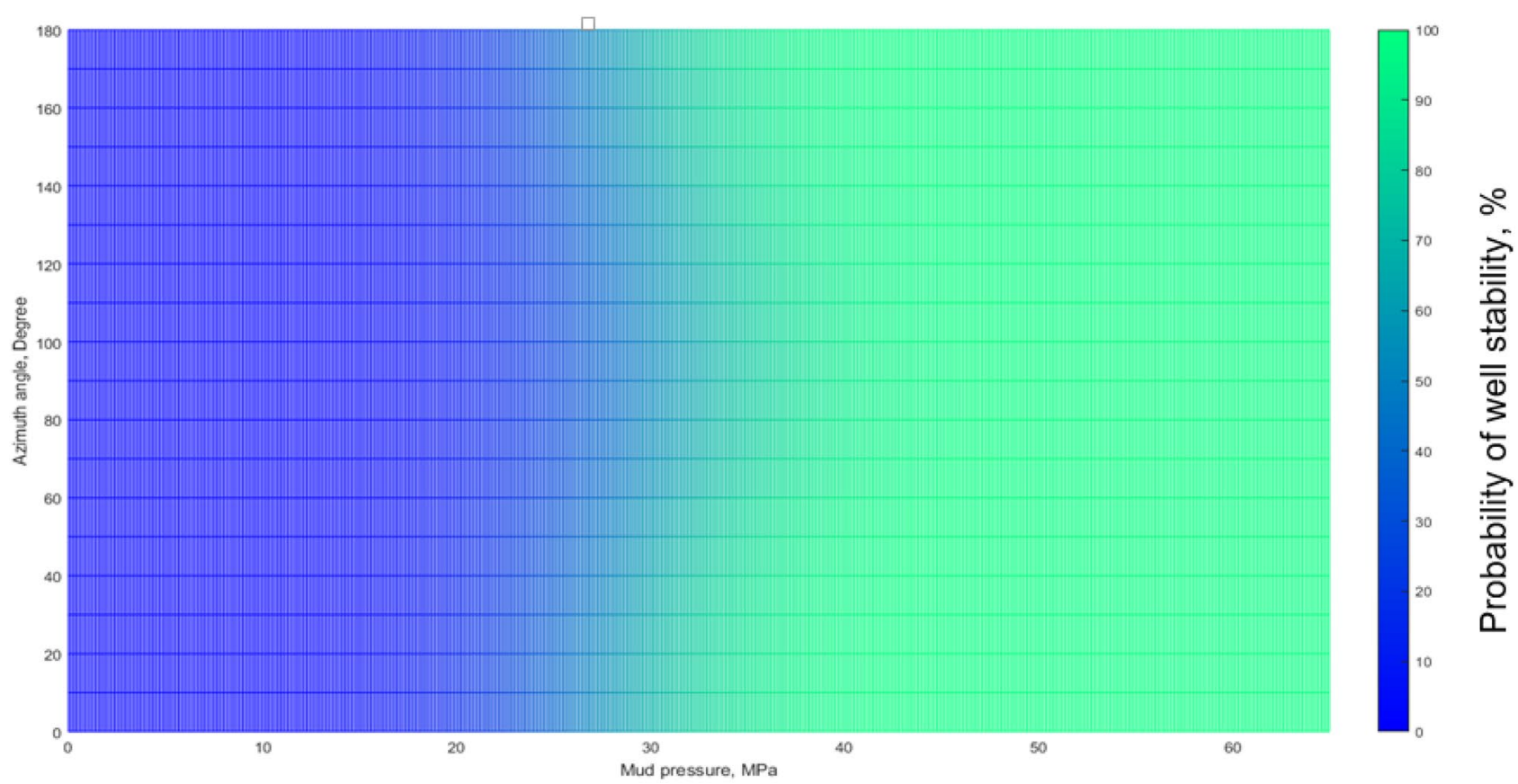

Fig. 3 Probability of well stability for different mud pressures and azimuth angles

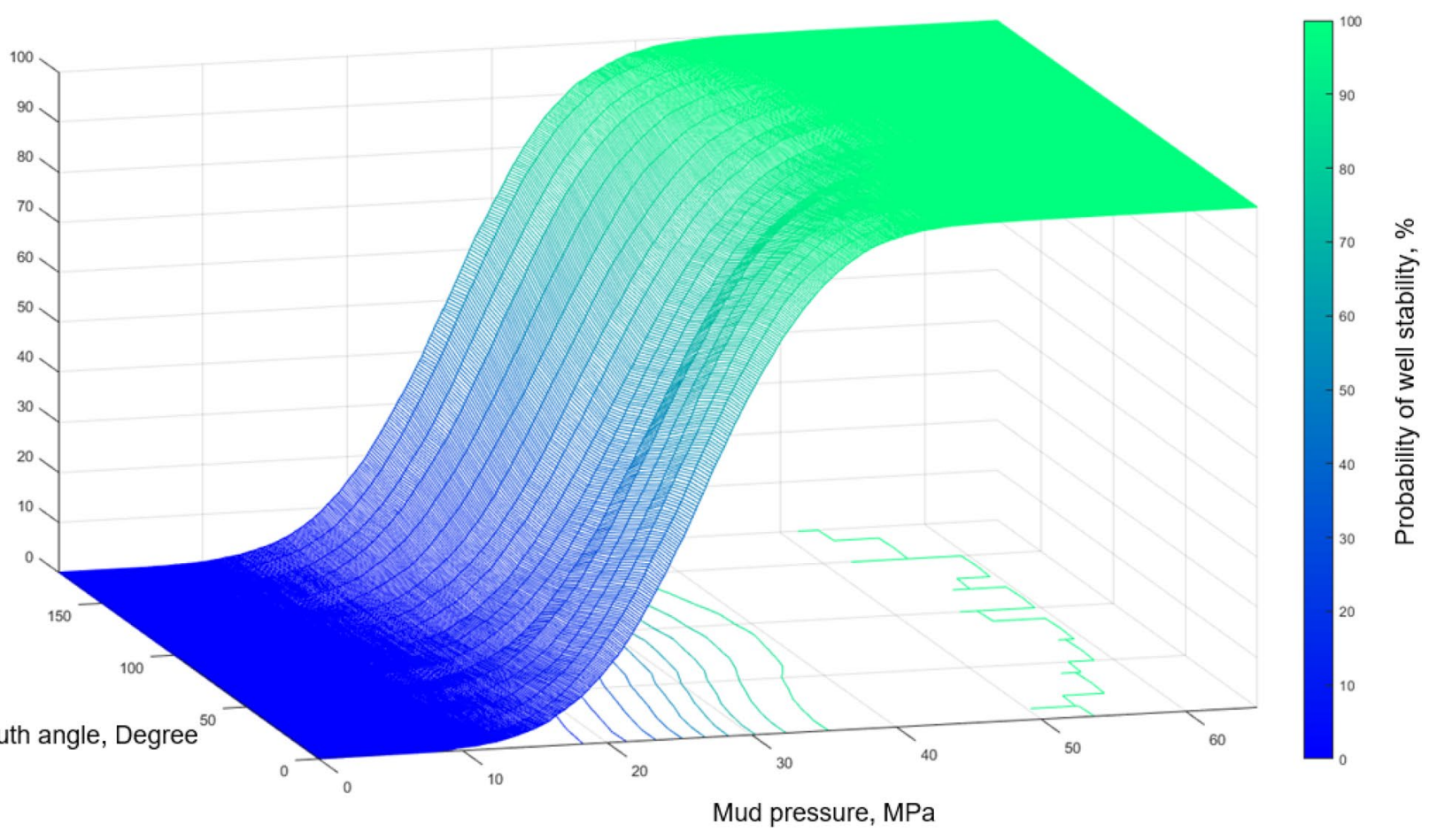

Fig. 4 Probability of well stability for different mud pressures and azimuth angles 
which is required to maintain the well stability. For example, referring to Fig. 2, it can be concluded that maintaining the mud pressure inside the wellbore as high as $40 \mathrm{MPa}$ leads to a $92 \%$ certainty level of wellbore stability.

\section{Conclusions}

Well instability problems are one of the most complicated and expensive issues especially for directional and horizontal wells. Stability analysis is essential to mitigate problems during well construction process. Stability of the well is affected by different factors, most of which are measured by indirect methods and therefore are subjected to some level of errors and uncertainties. This research investigates application of a Monte Carlo simulation technique to quantify the uncertainty associated with the output of a poroelastic geomechanical model. This approach enables us to make more reliable decision during mud pressure selection. Results of the Monte Carlo simulation show that at mud pressures larger than $50 \mathrm{MPa}$, probability of well stability is $100 \%$ for different azimuth angles. It also can be concluded that the probability of the well stability does not change significantly at different azimuth angles. However, drilling parallel to the direction of the minimum horizontal stress leads to higher probability of the well stability.

\section{Compliance with ethical standards}

Conflict of interest The authors declare that they have no conflict of interest.

\section{References}

1. Joshi SD (2003) Cost/benefits of horizontal wells. In: SPE western regional/AAPG Pacific section joint meeting. https://doi. org/10.2118/83621-MS

2. Abass HH, Warlick M, Pardo CH, Khan MR, Al-Tahini AM, Al-Shehri DA, Al-Badairy HH, Al-Shobaili YM, Finkbeiner T, Perumalla $S$ (2009) Evaluation of wellbore stability during drilling and production of open hole horizontal wells in a carbonate field. SPE Saudi Arab Sect Tech Symp. https://doi.org/10.2118/126157-MS

3. Moradi SST, Nikolaev NI, Chudinova IV, Martel AS (2018) Geomechanical study of well stability in high-pressure, high-temperature conditions. Geomech Eng 16(3):331-339. https://doi. org/10.12989/gae.2018.16.3.331

4. Simangunsong RA, Villatoro JJ, Davis AK (2006) Wellbore stability assessment for highly inclined wells using limited rock-mechanics data. SPE Annu Tech Conf Exhib. https://doi. org/10.2118/99644-MS

5. Aslannezhad M, Manshad KA, Jalalifar H (2015) Determination of a safe mud window and analysis of wellbore stability to minimize drilling challenges and non-productive time. J Petrol Explor Prod Technol 6(3):493-503. https://doi.org/10.1007/ s13202-015-0198-2

6. Zhanga J, Baib M, Roegiers JC (2003) Dual-porosity poroelastic analyses of wellbore stability. Int J Rock Mech Min Sci 40:473483. https://doi.org/10.1016/S1365-1609(03)00019-4

7. Gaoa J, Denga J, Lanb K, Fengc Y, Zhangd W, Wanga H (2017) Porothermoelastic effect on wellbore stability in transversely isotropic medium subjected to local thermal non-equilibrium. Int J Rock Mech Min Sci 96:66-84. https://doi.org/10.1016/j. ijrmms.2016.12.007

8. Zeynali ME (2012) Mechanical and physico-chemical aspects of wellbore stability during drilling operations. J Petrol Sci Eng 82-83:120-124. https://doi.org/10.1016/j.petrol.2012.01.006

9. Udegbunam JE, Aadnøy BS, Fjelde KK (2013) Uncertainty evaluation of wellbore stability model predictions. SPE/IADC Middle East Drill Technol Conf Exhib. https://doi.org/10.2118/16678 8-MS

10. Ding L, Wang Z, Liu B, Lv J, Wang Y (2019) Borehole stability analysis: a new model considering the effects of anisotropic permeability in bedding formation based on poroelastic theory. J Nat Gas Sci Eng 69:102932. https://doi.org/10.1016/j.jngse .2019 .102932

11. Manshad AK, Jalalifar H, Aslannejad M (2014) Analysis of vertical, horizontal and deviated wellbore stability by analytical and numerical methods. J Petrol Explor Prod Technol 4:359-369. https://doi.org/10.1007/s13202-014-0100-7

12. Knez $D$ (2014) Stress state analysis in aspect of wellbore drilling direction. Arch Min Sci 59(1):71-76. https://doi.org/10.2478/ amsc-2014-0005

13. He S, Wang W, Tang M, Hu B, Xue W (2014) Effects of fluid seepage on wellbore stability of horizontal wells drilled underbalanced. J Nat Gas Sci Eng 21:338-347. https://doi.org/10.1016/j. jngse.2014.08.016

14. Singh A, Seshagiri Rao K, Ayothiraman R (2019) An analytical solution to wellbore stability using Mogi-Coulomb failure criterion. J Rock Mech Geotech Eng 11:1211-1230. https://doi. org/10.1016/j.jrmge.2019.03.004

15. Al-Ajmi AM, Zimmerman RW (2006) Stability analysis of deviated boreholes using the Mogi-Coulomb failure criterion, with applications to some oil and gas reservoirs. IADC/SPE Asia Pac Drill Technol Conf Exhib. https://doi.org/10.2118/104035-MS

16. Gholami R, Moradzadeh A, Rasouli V, Hanachi J (2014) Practical application of failure criteria in determining safe mud weight windows in drilling operations. J Rock Mech Geotech Eng 6:1325. https://doi.org/10.1016/j.jrmge.2013.11.002

17. Moos D, Peska P, Finkbeiner T, Zoback M (2003) Comprehensive wellbore stability analysis utilizing quantitative risk assessment. J Petrol Sci Eng 38(3-4):97-109. https://doi.org/10.1016/S0920 -4105(03)00024-X

18. Gorji M, Kazemi A, Ganji DD (2014) Uncertainties due to fuel heating value and burner efficiency on performance functions of turbofan engines using Monte Carlo simulation. IJE Trans A Basics 27(7):1139-1148

19. Chan V (2013) Theory and applications of Monte Carlo simulations. InTech, London

Publisher's Note Springer Nature remains neutral with regard to jurisdictional claims in published maps and institutional affiliations. 